\title{
Successful management of serious disopyramide poisoning
}

\author{
D. W. HolT* \\ B.Sc., Ph.D. \\ M. Helliwell* \\ M.R.C.P. \\ B. O'KEEFFE $\dagger$ \\ B.Sc., M.R.C.P. \\ A. M. HAYLER* \\ B.Sc. \\ C. B. Marshall** \\ M.B. B.S. \\ G. CoOK** \\ M.B. B.S. \\ Poisons Unit* and Department of Cardiology†, Guy's Hospital, London, S.E.1, and \\ Bedford General Hospital**, Bedford
}

\begin{abstract}
Summary
A case of deliberate disopyramide overdosage is described. Circulatory collapse was treated by means of a large dose of isoprenaline, and charcoal haemoperfusion was used in an attempt to enhance the elimination of disopyramide. The suitability of this treatment regime is discussed in the light of findings from animal studies and the implications for the management of the disopyramide-poisoned patient are considered.
\end{abstract}

\section{Introduction}

The accidental or deliberate ingestion of significant overdose quantities of the antiarrhythmic drug disopyramide carries a poor prognosis. Three reports have documented such cases in all of which death ensued, either before admission to hospital or within $48 \mathrm{hr}$ of admission (Hayler, Holt and Volans, 1978; Hutchison and Kilham, 1978; Powell, Smith and Carey, 1978). No reports can be traced of survival following overdose with this drug.

A case is now reported of serious disopyramide overdosage in which the patient was successfully managed using a treatment regime based on experimental findings from animal studies (Hayler et al., 1979; O’Keeffe et al., 1979).

Plasma disopyramide concentrations were measured using a specific gas-liquid chromatographic technique (Hayler and Flanagan, 1978).

\section{Case history}

A 21-year-old male was admitted to hospital one hour after ingesting $200 \times 100$-mg capsules of disopyramide (Rythmodan) which had been prescribed for his mother.

Correspondence: Dr D. W. Holt, Poisons Unit, New Cross Hospital, Avonley Road, London SE14 5ER.

On arrival he was conscious, co-operative and orientated, but complained of dry mouth, blurred vision and paraesthesiae of the limbs. On examina-음 tion he was peripherally well perfused, the pulse wasirregular with a rate of 90 beats/min and BP was $D$ $90 / 50 \mathrm{mmHg}$. Heart sounds were normal, the chest was clear and bowel sounds were scanty. The ECG $\vec{\circ}$

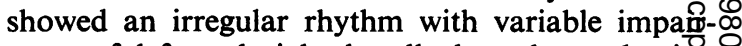
ment of left and right bundle branch conduction (Fig. 1).

Initial treatment consisted of gastric lavage which yielded a large quantity of fragmented capsules and the patient was transferred to the ICU.

One hour after admission he suddenly became

I

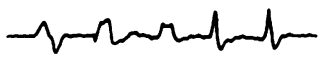

II

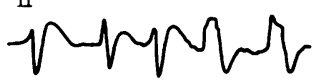

III

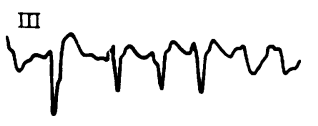

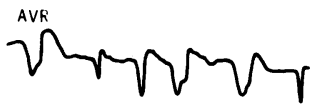
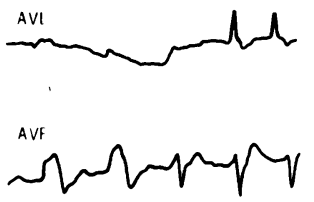

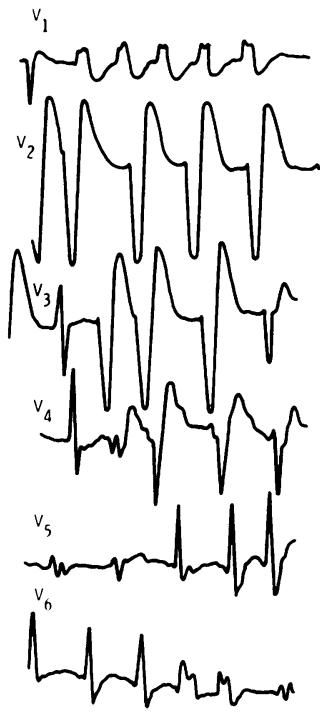

FIG. 1. 12-lead ECG on admission to hospital. 
confused and cyanosed, and his BP was unrecordable. The ECG monitor showed the same rhythm as on admission. A bolus of $2 \mathrm{mg}$ isoprenaline was given by slow i.v. injection over $5 \mathrm{~min}$, when the BP returned to $110 / 70 \mathrm{mmHg}$, without any change on the ECG. The patient was given oxygen and a CVP line was inserted, giving a reading of $3 \mathrm{~cm}$ water. Blood was taken for blood gas estimations and clinical chemistry investigations, which revealed the following, all in $\mathrm{mmol} / \mathrm{l}$ :

$\mathrm{Na}^{+}, 145 ; \mathrm{K}^{+}, 2 \cdot 8 ; \mathrm{Cl}^{-}, 97 ; \mathrm{HCO}_{3}{ }^{-}, 23$; urea,

7.6; and the following: $\mathrm{pH}, 7 \cdot 46 ; \mathrm{PCO}_{2}, 2.0 \mathrm{kPa}$;

$\mathrm{Po}_{2}, 18.8 \mathrm{kPa}$; base excess 8.9 .

The plasma disopyramide concentration was 16.5 $\mathrm{mg} / \mathrm{l}$ (effective range 2-4 mg/l (Mason, 1978).

Subsequently, blood samples were collected frequently for the monitoring of serum electrolytes and disopyramide concentrations.

Following the bolus dose of isoprenaline, an infusion of this drug at the rate of $40 \mu \mathrm{g} / \mathrm{min}$ was started, being gradually reduced to $13 \mu \mathrm{g} / \mathrm{min}$ over the first $30 \mathrm{~min}$. At this time a supraventricular tachyarrhythmia developed (Fig. 2), which spontaneously reverted to sinus rhythm when the isoprenaline infusion was stopped. Thereafter, systolic BP was maintained in the range $70-100 \mathrm{mmHg}$ by means of an isoprenaline infusion at the rate of $1-5 \mu \mathrm{g} / \mathrm{min}$; the infusion was discontinued for periods of up to $20 \mathrm{~min}$ if a tachyarrhythmia of the type shown in Fig. 2 was noted.

Hypokalaemia was corrected by the infusion of $3 \mathrm{~g} \mathrm{KCl}$ over $2 \mathrm{hr}$. Bladder catheterization revealed the patient to be anuric and, although $80 \mathrm{mg}$ frusemide i.v. failed to produce a diuresis, $250 \mathrm{ml}$ of $25 \%$ mannitol elicited a brisk urine flow of 600 $\mathrm{ml} / \mathrm{hr}$.

Five hours after admission haemoperfusion was started using a $2 \%$ acrylic hydrogel coated charcoal column (Haemocol-100, Smith \& Nephew Research Ltd, U.K.) inserted into an $A / V$ shunt in the left wrist. By that time, the BP was stable at $90 / 50$ $\mathrm{mmHg}$, without the use of isoprenaline, and a blood flow of $200 \mathrm{ml} / \mathrm{min}$ was maintained through the column. The ECG showed sinus rhythm with first degree heart block, together with left and right bundle conduction impairment, interspersed with atrial tachycardia showing a variable $1: 1 / 2: 1$ conduction to the ventricles. Serum $\mathrm{K}^{+}$was then $3.8 \mathrm{mmol} / \mathrm{l}$.

During the following $2 \mathrm{hr}$ there was a steady increase in BP to $120 / 80 \mathrm{mmHg}$ and the ECG showed narrowing of the QRS complexes and a PR interval of $0.28 \mathrm{sec}$. The patient was alert but still complained of mild anticholinergic side effects. Bowel sounds were present at this time.

Haemoperfusion was continued in all for $10 \mathrm{hr}$.

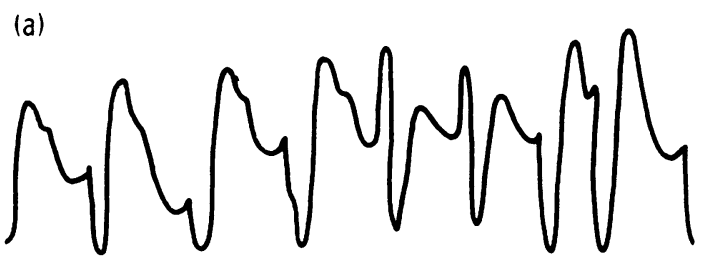

(b)

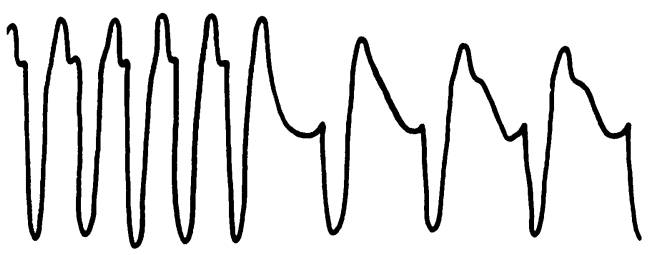

(c)

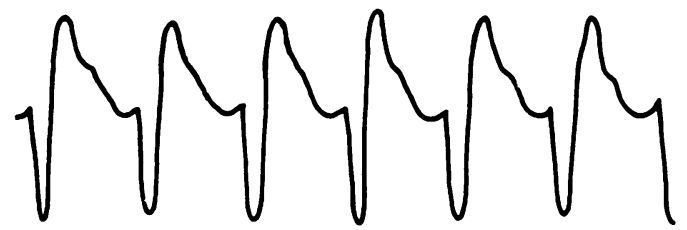

FIG. 2. ECG rhythm strips. (a) Before bolus dose of isoprenaline. (b) During isoprenaline infusion. (c) Following termination of isoprenaline infusion.

After $7 \mathrm{hr}$ an uncoated charcoal column was used (B-D Hemodetoxifier, Becton-Dickinson and Co., U.S.A.); blood flow through this column was maintained at $300 \mathrm{ml} / \mathrm{min}$. Throughout the whole period of haemoperfusion, blood samples were drawn from both the column inlet and outlet lines for the measurement of disopyramide. The plasma concentrations are shown in Fig. 3, whilst the clearance data and amounts of drug removed by haemoperfusion are shown in Table 1.

Following this procedure, the patient remained in the ICU for a further $24 \mathrm{hr}$ during which time the

TABLE 1. Clearance data and amounts of disopyramide removed by haemoperfusion

\begin{tabular}{lcc}
\hline Cartridge type & 'Haemocol 100' & 'B-D Hemodetoxifier' \\
\hline $\begin{array}{l}\text { Perfusion time } \\
\text { (hr) }\end{array}$ & 7 & 3 \\
$\begin{array}{l}\text { Mean clearance } \\
\text { (ml/min) }\end{array}$ & 26.4 & $35 \cdot 5$ \\
$\begin{array}{l}\text { Mean inlet plasma } \\
\text { concentration (mg/l) }\end{array}$ & 9.6 & 4.4 \\
$\begin{array}{l}\text { Theoretical amount } \\
\text { removed (mg) }\end{array}$ & 106 & 28 \\
\hline
\end{tabular}




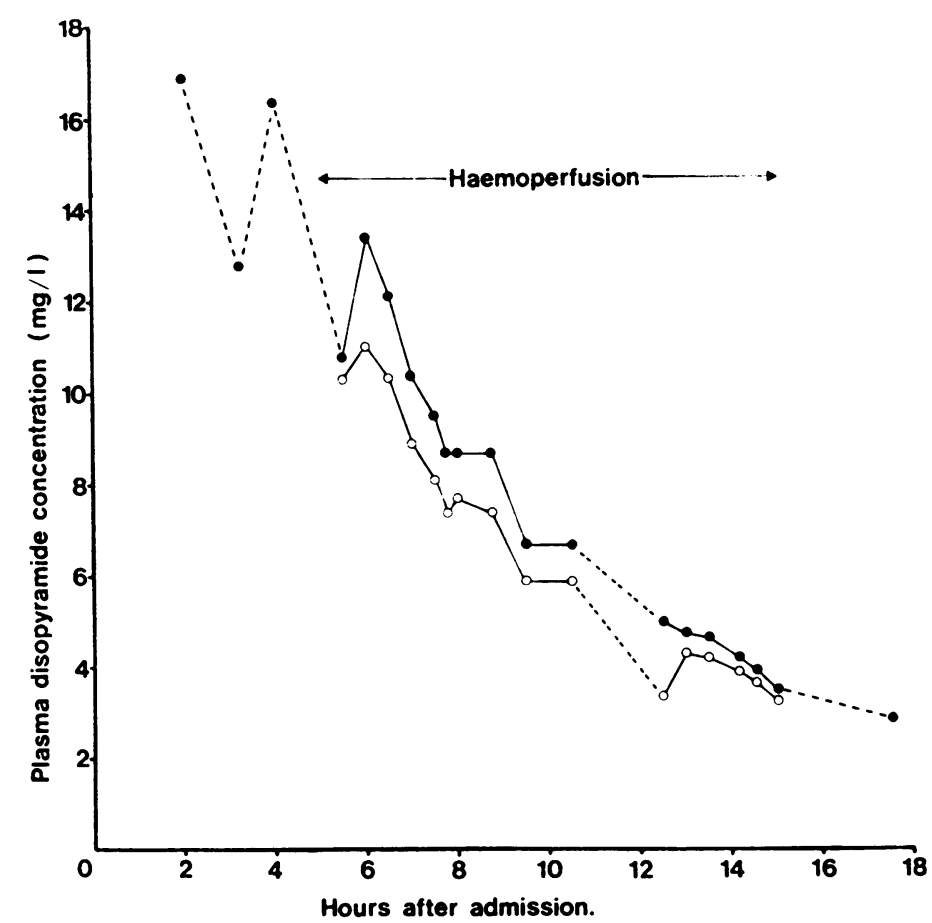

FIG. 3. Plasma disopyramide concentrations. During the period of haemoperfusion, concentrations from both the column inlet $(O)$ and outlet $(O)$ lines are shown.

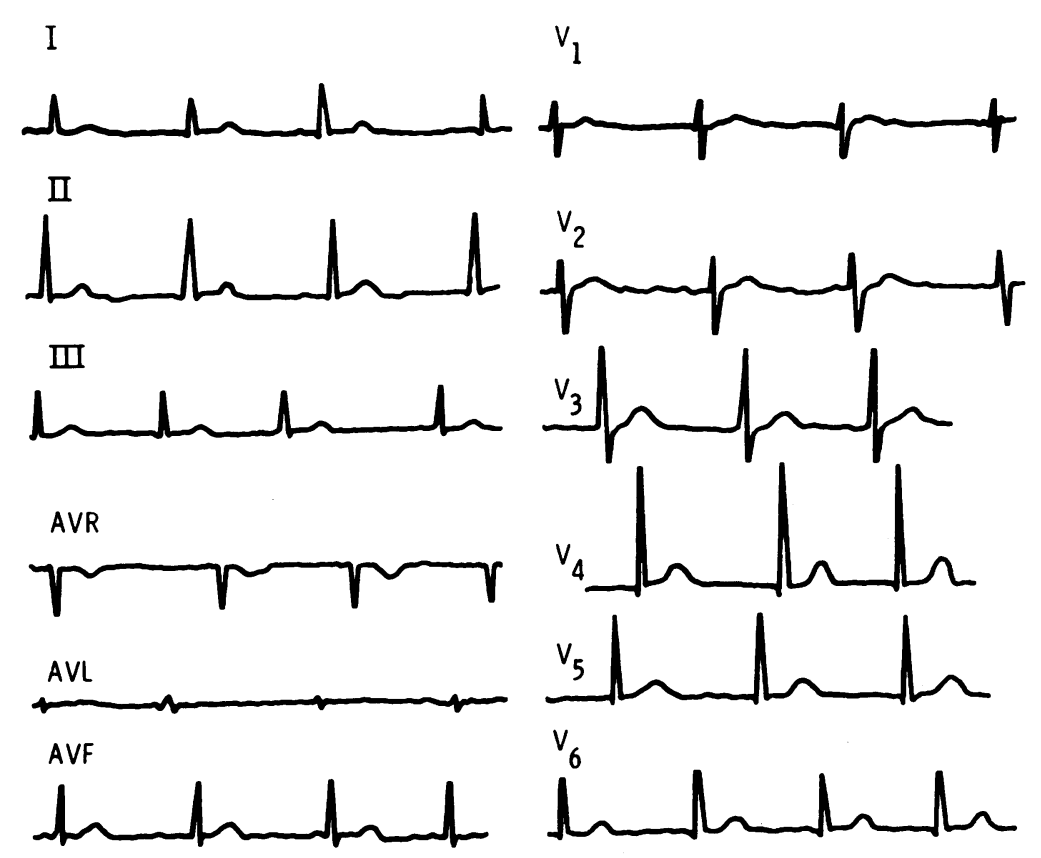

FIG. 4. 12-lead ECG $24 \mathrm{hr}$ after admission to hospital. 
CVP line and urethral catheter were removed. The shunts were clamped and then removed after 3 days. The ECG showed sinus rhythm (Fig. 4), and the patient was transferred to a general ward, where further recovery was uneventful. He was discharged 7 days after the overdose.

\section{Discussion}

Previous reports of disopyramide poisoning have noted an early loss of consciousness, cardiac or respiratory arrest and both tachy- and bradyarrhythmias (Hayler et al., 1978; Hutchison and Kilham, 1978; Powell et al., 1978). Despite intensive care and, in several cases, apparent response to resuscitation, in all instances the patient died.

The sequence of events following disopyramide overdosage has been elucidated by means of an animal model (O'Keeffe et al., 1979). A consistent finding in dogs poisoned with the drug was circulatory collapse, resulting in a sudden drop in systolic BP and cardiac output, which occurred without obvious premonitory signs on the ECG. Respiratory and cardiac problems were secondary to this event. If therapy was instituted rapidly, the circulation could be restored by an inotropic drug, consistently good results being obtained with isoprenaline. In addition, experimental work has shown that the drug can be removed rapidly by charcoal haemoperfusion, up to $40 \%$ of a large overdose being removed within $3 \mathrm{hr}$ (Hayler et al., 1979).

Disopyramide has a mild anticholinergic action which can cause side effects such as dry mouth, blurred vision and urinary hesitancy. The patient in this case showed classic symptoms of disopyramide excess and shortly after the time of circulatory collapse the plasma disopyramide concentration was very high. The plasma concentrations were below those expected for the ingestion of $20 \mathrm{~g}$ disopyramide, (A. Hayler, unpublished observation) which the patient insisted he had taken, suggesting the effectiveness of the stomach wash-out. During the first $6 \mathrm{hr}$ after admission to hospital, plasma concentrations fluctuated, consistent with prolonged absorption from a mass of capsules in the gut.

The key to the management of this patient was the prompt use of a large dose of isoprenaline, following the sudden loss of BP. Clinical problems subsequent to this were most probably due to high dose isoprenaline infusion and hypokalaemia.

The ECG on presentation showed an irregular rhythm with multiform abberrant complexes which, at first sight, may suggest multifocal ventricular ectopic activity. However, atrial activity is not clearly seen (the $P$ wave becomes increasingly slurred and of low amptitude with toxic concentrations of disopyramide) and caution is necessary in inter- preting this record, which may equally represent conducted rhythm with varying block in the HisPurkinje system.

Primary ventricular arrhythmia has been reported in association with disopyramide administration (Nicholson et al., 1979; Meltzer et al., 1978), but only in patients with pre-existing heart disease. In other cases, without underlying cardiac disease (Hayler et al., 1978; Powell et al., 1978), the suspicion exists that ventricular arrhythmias occurred secondary to circulatory collapse and were, essentially, agonal.

Where ventricular tachycardia does occur, the properties of disopyramide favour the atypical 'torsade de pointes' variety (Krikler and Curry, 1976). Under these circumstances it is advisable to maintain a normal serum potassium concentration, since hypokalaemia promotes this type of arrhythmia (Curry et al., 1976). In addition, it has been emphasized previously (Hayler et al., 1979) that the use of cardio-depressant antiarrhythmic drugs following disopyramide overdosage is likely to exacerbate the problem. Indeed, the authors are aware of a case of disopyramide poisoning, in which the drug was not initially implicated, in which a mistaken diagnosis of ventricular tachycardia resulted in the i.v. administration of disopyramide in an (unsuccessful) attempt at treatment!

In the present case, large doses of isoprenaline resulted in restoration of the circulation, reflecting results obtained in experimental disopyramide poisoning (O'Keeffe et al., 1979). During isoprenaline infusion the ECG showed rapid conducted rhythm, up to 170 beats/min, probably representing either sinus or focal atrial tachycardia. Abrupt halving and doubling of the ventricular rate (Fig. 2) suggested intermittent $2: 1$ atrioventricular block.

As the plasma disopyramide concentrations fell, the ECG changes resolved. Atrial activity, initially with first degree atrioventricular block, became evident and the QRS complex became progressively narrower until, $36 \mathrm{hr}$ after ingestion of disopyramide, the ECG was within normal limits.

Whilst symptoms and signs improved during the early period of haemoperfusion no specific benefit can be attributed to the technique in this case since it removed very little of the drug. The poor clearance of disopyramide in this case, using the Haemocol 100 , was almost identical with the in vitro clearance determined subsequently (Hayler et al., 1979), and it would appear that this column is unsuitable for the rapid elimination of disopyramide. The results using the B-D Hemodetoxifier were particularly disappointing since this column has given in vitro and, in dogs, in vivo clearances in excess of $90 \mathrm{ml} / \mathrm{min}$ for disopyramide (Hayler et al., 1979). Since a good blood flow was maintained in the present case, it is 
possible that the column used in this instance was defective in some respect.

The role of haemoperfusion in the treatment of disopyramide overdosage has yet to be established. The outcome in this case indicates that the prompt treatment of circulatory collapse was of prime importance, but active removal of the drug from the body might be of clinical value in a patient with a very high plasma disopyramide concentration and known cardiac disease.

As far as can be ascertained, this is the first report of an established case of serious disopyramide overdosage in which the patient has survived. Treatment was based on observations made in animal studies and the findings in this case suggest that the cardiovascular consequences of disopyramide poisoning are reversible by the timely use of an inotropic agent.

\section{Acknowledgments}

We thank Dr W. D. Riding for permission to publish details of a patient under his care, and Dr R. Goulding for his helpful criticism of the manuscript.

\section{References}

Curry, P.V.L., Stubbs, W., Fitchett, D. \& Krikler, D.M. (1976) Ventricular arrhythmias and hypokalaemia. Lancet, ii, 231.

Hayler, A.M. \& Flanagan, R.J. (1978) Simple gas-liquid chromatographic method for the measurement of diso-صِ pyramide in blood-plasma or serum and in urine. Journal of Chromatography, 153, 461.

HAYLeR, A.M., HolT, D.W., O'KeEFFe, B. \& MedD, R.K. 요

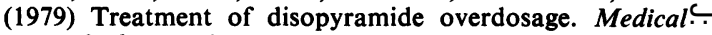
Journal of Australia, 1, 234.

Hayler, A.M., Holt, D.W. \& Volans, G.N. (1978) Fatal overdosage with disopyramide. Lancet, i, 968.

HAYLeR, A.M., MedD, R.K., Holt, D.W. \& O'KeefFe, B.D. (1979) Experimental disopyramide poisoning: treatment by cardiovascular support and with charcoal $\frac{5}{\top}$ haemoperfusion. Journal of Pharmacology and Experi- $\stackrel{\mathbb{Q}}{\mathcal{Q}}$ mental Therapeutics 211, 491.

Hutchison, A. \& KilhaM, H. (1978) Fatal overdosage of के disopyramide in a child. Medical Journal of Australia, 2, $\overrightarrow{0}$ 335.

KRIKLeR, D.M. \& Curry, P.V.L. (1976) Torsade de pointes $\overrightarrow{\vec{\omega}}$ -an atypical ventricular tachycardia. British Heart $\mathcal{W}$ Journal, 38, 117.

MASON, D.T. (1978) Disopyramide: A new agent for effective $\frac{C}{3}$ therapy of ventricular dysrhythmias. Drugs, 15, 329.

Meltzer, R.S., ROBERT, E.W., MCMORROW, M. \& Martin, if R.P. (1978) Atypical ventricular tachycardia as a manifestation of disopyramide toxicity. American Journal of $S$ Cardiology, 42, 1049.

Nicholson, W.J., Martin, C.E., Gracey, J.G. \& Knock, 心 H.R. (1979) Disopyramide-induced ventricular fibrillation. $ه$ American Journal of Cardiology, 43, 1053.

O'KeEfFe, B., HAYler, A.M., Holt, D.W. \& MedD, R.K. (1979) Cardiac consequences and treatment of disopyra- $>$ mide intoxication; experimental evaluation in dogs. Cardio-을
vascular Research 13, 630 .

Powell, F., Smith, P. \& CAREy, O. (1978) Fatal disopyramide $\vec{\bullet}$ overdose. Journal of the Irish Medical Association, 71, $5 \$$ 